\title{
Quando o dizer de um sujeito é objeto de pesquisa: contribuições da Análise do Discurso Francesa para a compreensão da fala de professores em situação de entrevista
}

When the saying of a subject is object of research: contributions of Analysis of Discourse French to understand the speech of teachers in a position to interview

Cristhiane Cunha Flôr ${ }^{1}$

Suzani Cassiani de Souza ${ }^{2}$

\section{Resumo}

No presente trabalho apresentamos algumas contribuições da Análise do Discurso Francesa para a compreensão da fala de professores em situação de entrevista. Para tanto, apresentamos um dos conceitos-chave da Análise do Discurso em funcionamento na interlocução com entrevistas feitas com professores: as condições de produção, que implicam em relações de sentido, relações de forças e mecanismos de antecipação. Trazemos também os conceitos de memória discursiva, não-dito e não transparência da linguagem articulados ao texto. Colocamos esses conceitos em funcionamento ao analisar uma situação de entrevista realizada com professores de ciências do ensino fundamental, onde estes falam sobre histórias de sucesso ao dar aulas de ciências e também sobre sua relação com os PCN's.

Palavras-chave: Análise do discurso, condições de produção, análise de entrevistas.

\begin{abstract}
This present work shows some contributions of the French Analysis of Discourse for the understanding of the teachers speech in interview situations. To achieve that, we worked on one of the key concept of the Analysis Discourse developed in the dialogue with interviews done with teachers: the Production Conditions, which implicate in relationships of meaning, relationships of forces and anticipation mechanisms. We also used the concepts of discursive memory, no-said concept and no transparency of the language articulated to the text. Those concepts were brought to analyze the interview with teachers of sciences of the fundamental teaching about their success histories when giving classes of sciences and also about their relationship with PCN's.
\end{abstract}

Key-words: Analysis of Discourse, production conditions, analysis of interviews.

${ }^{1}$ Doutoranda do Programa de Pós-graduação em Educação Científica e Tecnológica - UFSC.

2 Professora no Programa de Pós Graduação em Educação Científica e Tecnológica - UFSC. 


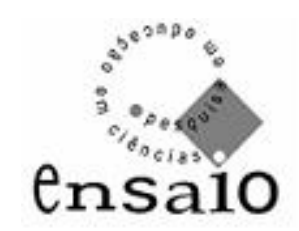

Vol. 10 no. 1 jun. 2008

\section{A pesquisa em ensino de ciências e a linguagem}

Os estudos a respeito de questões da linguagem vêm ganhando importância cada vez maior na área de ensino de ciências. Na edição comemorativa dos 25 anos do International Journal of Science Education, YORE, BISANZ e HAND (2003) apresentaram uma revisão da literatura a respeito de pesquisas que estudam as relações entre linguagem e ensino de ciências, na qual apontam um aumento de pesquisas neste campo, tanto no que se refere ao ensino e aprendizagem quanto no que se refere às metodologias de pesquisa e análise de dados.

Falando especificamente do Brasil, os temas referentes às questões de linguagem também têm merecido a atenção dos pesquisadores em ensino de ciências. Há trabalhos direcionados à produção e utilização de livros didáticos (AGUIAR JR, LIMA e MARTINS 2005, NAGEM e MARCELOS 2005, GIRALDI e SOUZA 2005) e aqueles visando compreender interações discursivas em sala de aula (FERREIRA e LORENCINI JR 2005, LIMA, PINHEIRO, SANTOS e NÉRI 2005, SCARPA e TRIVELATO 2005). Há também aqueles que estudamos a utilização de analogias na formação de professores (LIMA e NUÑEZ, 2006) e a polissemia do termo orgânico entre graduandos dos cursos de farmácia e química em universidades de São Paulo (SCHAFFER e REZENDE, 2006) tendo como base a análise de conteúdo. Outros pesquisadores utilizam a análise do discurso enquanto ferramenta metodológica de análise de dados (MORTIMER, MASSICAME, TIBERGHIEN e BUTY 2005, AMARAL e MORTIMER, VILLANI e CARVALHO 2005) entre outros.

Quando falamos em linguagem, vemos a importância de esclarecer seu significado. Para a análise do discurso francesa (AD) referencial por nós utilizado, é fundamental ocupar-se não com a gramática ou com a língua, mas com o discurso, entendido aqui como "efeito de sentidos entre interlocutores" (ORLANDI, 2003).A AD busca estudar o contexto mais amplo, do social ao ideológico, para detectar suas influências na linguagem. Dentro deste contexto, o presente trabalho situa-se entre aqueles que têm como tema central as questões de linguagem envolvidas no ato da pesquisa, principalmente na construção de um referencial para a análise das falas obtidas em situação de entrevista. 


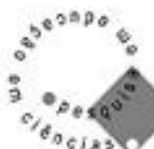 \\ ensa10}

Vol. 10 no. 1 jun. 2008

\section{O pesquisador e as leituras}

Na pesquisa em ensino de ciências, lidamos em muitas situações com material simbólico, desde a análise de livros didáticos até a situação da entrevista, passando também pela análise de vídeos e de diários de campo. Uma grande parte de nosso trabalho consiste então na leitura desses materiais. Leitura esta que, por se tratar de uma análise, obviamente não pode nem deve ser feita ao acaso, porém, à luz de um referencial. Considerando a importância de lançar um olhar diferenciado a essa questão, no presente trabalho, tratamos da análise do discurso de linha francesa ${ }^{1}$ enquanto referencial teórico e metodológico e suas implicações para a pesquisa, particularmente na área do ensino de ciências.

Por termos na maioria das vezes uma formação em cursos de ciências naturais (química, biologia, física e matemática), estamos habituados a escrever e ler relatórios de situações experimentais de uma forma dita "objetiva”, no sentido que SCHAFF (1983) coloca como “destituído de emoções”. Considerando a formação de cientistas em uma visão kuhniana, esta forma de escrever e ler relatórios faz parte do treinamento em um determinado paradigma e comunidade científica. Nestes momentos, tendemos a ter certeza de que o leitor atribuirá sentidos únicos e determinados aos termos que utilizamos, em virtude da preterida objetividade.

Esta certeza pode levar à ilusão de que a linguagem é transparente, ou seja, o que escrevemos será lido da forma como imaginamos. SILVA (2004, p.2) alerta para este fato ao colocar que:

O problema da transparência da linguagem talvez esteja relacionado a um certo imaginário positivista associado à necessidade que temos de evidências. Ora, para ser científico, seria preciso tratar nossos achados analíticos como se eles estivessem lá. Ora, a $A D$ não diz que não existem sentidos, mas diz que os sentidos não estão nos textos ou nas imagens. Para a $A D$ a evidência de que o sentido está no texto, na fala, na imagem, é já um efeito do funcionamento da linguagem. Funcionamento que é fundamental e essencialmente histórico e ideológico.

\footnotetext{
${ }^{1}$ Ao mencionarmos a Análise do Discurso neste trabalho estaremos nos referindo àquela de linha francesa, que tem em suas bases os trabalhos de Pêcheux.
} 


\section{3 \\ ensalo}

Vol. 10 no. 1 jun. 2008

Para a análise do discurso, a linguagem não é transparente, já que leitores distintos podem atribuir distintos significados ao mesmo termo. Precisamos então ter cuidado ao lidar com “dados empíricos” relacionados à linguagem, pois estes devem ter uma "âncora" histórico-ideológica, que pode ser conseguida ficando atentos às condições de produção desses discursos e de sua leitura. Para ORLANDI (1996):

Falar em discurso é falar em condições de produção e, em relação a essas condições gostaríamos de destacar que, como exposto por Pêcheux (1979), são formações imaginárias, e nessas formações contam a relação de forças (os lugares sociais dos interlocutores $e$ sua posição relativa no discurso), a relação de sentido (o coro de vozes, a intertextualidade, a relação que existe entre um discurso $e$ outros) e a antecipação (a maneira como o locutor representa as representações de seus interlocutores e vice-versa) (idem, p. 158).

A análise do discurso não é apenas referencial metodológico e no presente trabalho é utilizada também como referencial teórico, uma vez que partimos do princípio da não transparência da linguagem e do discurso como efeito de sentidos entre interlocutores. Baseadas nesta visão apresentamos a seguir a construção das condições de produção das leituras de cinco professores de ciências de $5^{\mathrm{a}}$ a $8^{\mathrm{a}}$ séries da rede pública estadual de Florianópolis. Este trabalho faz parte de um estudo mais amplo, onde buscamos as leituras dos professores de ciências do ensino fundamental sobre as histórias da ciência².

\section{Caracterizando a produção dos dizeres - Os lugares sociais dos entrevistados}

Para a realização da pesquisa que deu origem ao presente trabalho entrevistamos cinco professores da rede pública de ensino, licenciados em ciências, com experiência em turmas de oitava série e que possuíam as seguintes características:

* Em sua formação inicial, três dos entrevistados têm licenciatura plena em ciências biológicas enquanto dois têm licenciatura curta em ciências, sendo que um deles fez uma complementação para licenciatura plena; quanto à pós-graduação,

\footnotetext{
${ }^{2} \mathrm{O}$ trabalho citado deu origem à dissertação de mestrado de uma das autoras, intitulada LEITURAS DOS PROFESSORES DE CIÊNCIAS DO ENSINO FUNDAMENTAL SOBRE AS HISTÓRIAS DA CIÊNCIA que pode ser acessada na íntegra em www.ppgect.ufsc.br.
} 
Vol. 10 nํ. 1 jun. 2008

os cinco professores tiveram acesso. Três deles têm curso de especialização (lato sensu) e os outros dois em formação na época da pesquisa (stricto sensu).

* Em relação ao tempo de atuação lecionando ciências, todos têm mais de quinze anos de serviço. Esta ocorrência se deve em parte por um dos critérios de escolha ter sido a opção por professores efetivos na rede pública. Os professores habilitados em ciências ainda são poucos e a ocorrência dos concursos também limita a efetivação dos mesmos.

Estas considerações a respeito das características pessoais e profissionais dos entrevistados auxiliam bastante na composição de um perfil. O fato de serem todos professores efetivos de escolas públicas, por exemplo, os situa em um lugar social particular, onde geralmente salários baixos, carga horária elevada, turmas lotadas, falta de material e uma série de outras dificuldades interferem no seu fazer pedagógico. Se por um lado este quadro desestimula o professor, por outro muitas vezes o torna mais criativo, em busca de alternativas em prol de uma educação de qualidade.

As entrevistas com os cinco professores foram realizadas no âmbito de um estudo mais amplo, que buscava trazer à tona as leituras de professores de ciências do ensino fundamental sobre as histórias da ciência. As questões feitas aos professores giraram em torno de quatro eixos:

* A história de sucesso: pedimos que cada entrevistado relatasse uma história de sucesso ao lecionar ciências com o objetivo de tornar o ambiente da entrevista menos formal;

* Questões relativas aos Parâmetros Curriculares Nacionais: visando identificar sua influência na prática dos professores e traços desta em suas leituras sobre histórias da ciência;

* Aspectos relativos à história da ciência: para buscar indicativos das leituras que os professores fazem sobre o tema e da forma como eles a entendem;

* Sobre a atuação em turmas de oitavas séries: vislumbrando as histórias da ciência como uma possibilidade de contribuir para a superação das dificuldades muitas vezes encontradas ao trabalhar com essas turmas. 


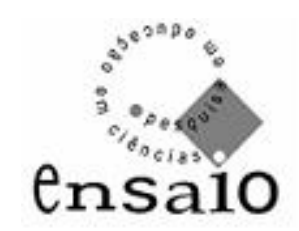

Vol. 10 no. 1 jun. 2008

Com base nestes eixos que nortearam o roteiro, demos início à aplicação das entrevistas que foram gravadas e posteriormente transcritas. As entrevistas foram realizadas individualmente, e, para tanto, o pesquisador acompanhava o roteiro com os eixos relativos às questões propostas.A transcrição das falas foi feita integralmente.

Para o presente trabalho, onde centramos o foco no estabelecimento das condições de produção das leituras dos professores, iremos apresentar falas relativas ao primeiro e ao segundo eixos.

\section{As histórias de sucesso e as condições de produção das leituras}

Iniciamos as entrevistas pedindo que os professores relatassem uma história que consideravam de sucesso ao dar aulas de ciências. Foram realizados quatro pilotos com a intenção de aprimorar o roteiro da entrevista.Por considerarmos fundamental a compreensão da entrevista como espaço de conversa, onde o pesquisador deve conhecer o mundo com o qual pretende interagir, optamos por uma introdução à entrevista que procurasse estabelecer um ponto de contato e conforto com o entrevistado, perguntando sobre seus sucessos ao atuar como professor de ciências, independente da série.

As histórias de sucesso relatadas nos permitiram acesso às visões dos professores entrevistados sobre a educação em ciências e a partir delas pudemos delinear as condições de produção de suas leituras.

Um ponto que destacamos é o fato de que os professores deixam ver, através de suas falas, alguns pontos de sua memória discursiva, de leituras já realizadas e que foram incorporadas, muitas vezes de forma inconsciente, ao seu discurso. Observamos por exemplo, na fala de alguns entrevistados, que estes muitas vezes estão atentos às modificações que vêm ocorrendo no ensino de ciências:

P1: Tem muita história interessante. Deixa eu ver... Bom, foi um projeto que foi desenvolvido na quinta série. Estudo de répteis.

P2: . Então a partir do momento que eles escolhiam os colegas, escolhiam os estudantes, aliás, o tema que eles gostariam de discutir, de estudar, aí então eu entrava como mediadora, né? Então eles iam buscar o conhecimento, eu orientava, mediava, apontava caminhos $e$ 


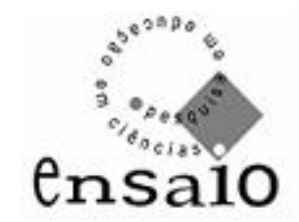

Vol. 10 no. 1 jun. 2008

eles iam buscar este conhecimento, eles iam produzir o próprio conhecimento.

O trabalho com projetos (P1) e a atuação como mediador na produção do conhecimento (P2), são temas atuais nas pesquisas em ensino, assim como em documentos oficiais e até mesmo em alguns livros didáticos. Dentre os autores que abordam estes temas, podemos citar CARVALHO (1998); HERNANDEZ e VENTURA; SOUZA (2000); DELIZOICOV, ANGOTTI e PERNAMBUCO (2002). Entendemos que as leituras já feitas pelo professor modificam a forma de olhar e praticar a educação.

A procura por superar o modelo tradicional, que prioriza a transmissão de conhecimentos por parte dos professores a um aluno passivo também faz parte das reflexões da maioria dos entrevistados em seus relatos de sucesso. Alguns deles têm buscado essa superação através da realização de trabalhos em grupo em consonância com CARVALHO (1998, p.31) a qual entende que “... é preciso que os estudantes compartilhem suas idéias com seus pares tanto em pequenos grupos como com toda a classe”.

P5: Então, na prática, a gente ia pra rua, levava a turma, dividia a turma em grupos, trabalhava sempre em equipes, combinava com eles, discutia com eles algumas tarefas que eles tinham que fazer, a gente ia organizando, entrando em acordo... Aí, fixava um objetivo, cada um, cada grupo tinha sua pranchetinha, seu material de anotação, e a gente ia pra rua.

Tanto P1, quanto P2, P3 e P5 nas suas atividades de sucesso relataram trabalhos em grupo demonstrando preocupações com as interações entre os alunos.

Em outros momentos, os professores demonstraram a preocupação em propiciar nas aulas de ciências situações que possibilitem ao aluno adquirir autonomia, ou seja, momentos nos quais eles possam tomar decisões e adquirir independência no desenvolvimento das atividades propostas. A autonomia tem sido apontada pela literatura como um importante aspecto a ser trabalhado pelo professor. Segundo CARVALHO (1998, p.29) “Criar alunos autônomos, que saibam pensar, tomar as próprias decisões e estudar sozinhos, é uma das metas do ensino”. Observamos esta preocupação em alguns momentos na fala dos entrevistados: 


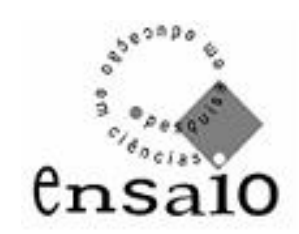

Vol. 10 nํ. 1 jun. 2008

P1: E os meninos de onze anos, eles decidiram fazer um estudo aprofundado da cobra de vidro [...] Só que é o seguinte: eles consequiram um exemplar da cobra de vidro, montaram um terrário e passaram a cuidar dela com todos os mimos possíveis, estudaram, leram muito, e foi um trabalho muito interessante de orientar.

P2: $\underline{O}$ objetivo maior desses eventos para mim era dar autonomia para o aluno, ta? Não impor somente os conteúdos que estão no currículo, né? E trabalhar conteúdos suqeridos por eles.

P3: O trabalho... Daí cultiva a horta, daí divide por concurso, a turma... Escolhia um canteiro pra cada turma, daí eles escolhiam o que iam plantar. E usava na merenda tudo isso que colhia, levava pra casa, a gente fazia isso muito lá.

Algumas vezes o professor falava diretamente sobre a autonomia (P1). Outras vezes, através de termos como decidiram e conseguiram, também identificamos no dizer do professor (P2) a mesma preocupação. No entanto, nem sempre trabalhar com a autonomia é fácil e muitas vezes os professores alternam momentos nos quais direcionam a atividade com outros nos quais possibilitam a tomada de decisões por parte dos alunos (P3).

Consideramos este tipo de atitude necessário e positivo, uma vez que trabalhar com autonomia não implica necessariamente em deixar ao encargo dos alunos as decisões sobre conteúdos e metodologias das aulas, mas sim possibilitar que ele tome decisões a respeito destes. E essa tomada de decisões significa uma mudança do foco de um ensino tradicional centralizado no professor para um centralizado na interação, na construção dos conceitos por parte dos alunos. Segundo ASTOLFI (1997, p.58) “o termo construtivismo no plano didático põe o aluno no centro das aprendizagens escolares.O ponto de vista construtivista opõe-se aqui ao ponto de vista transmissivo $\{\ldots\}$ “.

Neste esboço das condições de produção das leituras dos entrevistados através de traços comuns em sua fala, pudemos perceber que estes priorizaram aspectos metodológicos em suas histórias de sucesso, relatando melhorias e inovações em suas práticas pedagógicas. Em seu dizer transparecem leituras que eles possuem sobre temas atuais da pesquisa em educação em ciências, possivelmente provenientes de fontes diversas (Cursos de formação inicial e continuada, documentos oficiais, revistas educacionais entre outros). 


\section{ensaio}

Vol. 10 no. 1 jun. 2008

Além dos pontos em comum que encontramos nas falas dos professores, há também aqueles relativos ao que foi silenciado, pois, assim como ORLANDI (2003, p.84), entendemos que “... o que não é dito, o que é silenciado, constitui igualmente o sentido do que é dito". Chamou-nos a atenção a ausência de relatos envolvendo a história da ciência em atividades de sucesso, uma vez que esta inclusão também faz parte dos processos de inovação no ensino de ciências.

Um outro aspecto interessante é o fato de que, exceto P4, os outros entrevistados não mencionaram as oitavas séries em suas histórias de sucesso. Este silêncio corrobora a percepção de que alguns professores, devido a questões envolvidas em sua formação, apresentam dificuldades em trabalhar com esta série que aborda por tradição conteúdos da química e física.

\section{5 - Os PCN’s e as posições dos sujeitos-professores de ciências do}

\section{ensino fundamental}

O eixo das entrevistas relativo às histórias de sucesso nos permitiu traçar um perfil mais amplo dos sujeitos. Agora, voltamos nosso olhar às questões relativas aos PCN's, com o propósito de compreender um pouco da relação dos professores entrevistados com o documento. Compreendemos que, mesmo através da leitura indireta via livros didáticos, este documento pode fazer parte das condições de produção das leituras dos professores, no caso deste estudo específico, sobre as histórias da ciência e, no geral, sobre a educação.

Assim, compreendendo os PCN's como um possível discurso fonte, o qual faz parte do contexto histórico das escolas, levantamos alguns aspectos que consideramos relevantes. Apesar de termos percebido no perfil dos professores tentativas de inovações em sua prática pedagógica, parece que estes não vêem nos documentos oficiais uma fonte de aprofundamento de suas leituras. Além disso, os professores afirmam não ter tempo para debater:

P3: Eu... Quanto aos PCN's eu não sei te dizer nada, na verdade eu tenho uma cópia e a gente não tem aquele tempo assim de sentar, trabalhar, debater... 


\section{ensaio}

Vol. 10 no. 1 jun. 2008

É importante salientar, por exemplo, que muitos professores vêem os PCN's como algo imposto pelo MEC e que não teve um trabalho de implementação, o que possivelmente traz dificuldades à sua difusão no espaço escolar. O resultado pode ser um desprezo, como mostra P2:

P2: Porque as escolas que eu trabalhei os PCN’s, eles ficavam lá pra enfeitar as prateleiras, né?

Essas considerações abordam a falta uma indicação mais precisa das fontes onde o professor pode encontrar conhecimentos sobre os temas e metodologias sugeridos. Enfim, apesar de trazer indicações muito interessantes para os professores, não ajudam muito na compreensão de como por em prática as mudanças sugeridas.

Em relação aos documentos, quando questionados sobre a importância de seus indicativos, esses mesmos professores dizem que:

P2: Porque ali eles sugerem que você contextualize o dia-a-dia do aluno, né?

P3: Te entregam, fica e assim foi ficando.

Pudemos perceber nestas falas que os professores muitas vezes não se vêem como possíveis autores da proposta simbolizada pelo documento.Pelo contrário, dividem o território de sua leitura e ação em “nós” e “eles”. Possivelmente, “nós”, que não participamos da elaboração e agora somos chamados a pôr em prática algo que não conhecemos muito bem; “eles”, que elaboraram a proposta e não participam do cotidiano escolar.

Em outros momentos, as leituras realizadas pelos professores entrevistados parecem ter provocado um deslocamento na posição do sujeito, de professor para pesquisador: não se coloca ele próprio como professor, utilizando nesse momento a terceira pessoa:

P2: A minha preocupação é justamente como_ o professor irá conseguir...”

P5: É o próprio professor que tem dificuldade. 


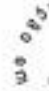

Vol. 10 no. 1 jun. 2008

Da mesma forma, outros entrevistados se colocam nessa posição ao falar

sobre os documentos:

P2: Alguns professores leram, outros nem leram.

P5: Porque os professores têm formação diferente, têm visões de mundo diferentes, né?

Está ausente o “eu” ou o “nós” professores presente anteriormente em outros dizeres, nos quais se assumem como professores. Neste momento, a posição que o sujeito ocupa está mais próxima do crítico, de quem olha de fora, do que propriamente de seu papel social de professor. São os professores que não lêem, que têm dificuldades, que possuem formações diferentes. Este deslocamento da posição relativa no discurso pode mostrar que os professores refletem sobre suas dificuldades, porém, para tanto, precisam se distanciar das mesmas.

Consideramos importante ainda, na tentativa de compor um esboço das condições de produção do discurso dos professores entrevistados (locutores), o mecanismo de antecipação das falas que se desenrola no espaço do imaginário. Para ORLANDI (1996), antecipação é o mecanismo através do qual

... o locutor experimenta o lugar de seu ouvinte a partir de seu próprio lugar [...] Quando digo que o locutor supõe o que o outro vai pensar, estou dizendo, em termos discursivos, que o locutor pretende saber a relação existente entre o que o interlocutor vai dizer e o seu lugar, e isto vai constituir o seu próprio (do locutor) dizer. (p. $126-$ 127)

Assim, na posição de professores de ciências, entrevistados, há respostas que não podem ser dadas ao falarem sobre determinado tema, no caso, os PCN's. É o que pudemos observar nas seguintes falas:

P3: Quanto aos PCN's eu não sei te dizer nada, [...] Acho que dentro dos PCN's sim porque eu estou levando então o aluno a conhecer alguma coisa a mais do que aquilo que tem no livro didático. É do dia a dia dele, ele convive.

P4: Então eu não posso realmente estar discordando. Eu posso discordar. Eu tenho uma opinião, A, B, C têm outra opinião. 
Vol. 10 no. 1 jun. 2008

Percebemos que $\mathbf{P 3}$ a princípio nega ter conhecimentos sobre os Parâmetros para, em seguida, mobilizar algumas de suas indicações como a superação do ensino meramente livresco e a utilização do dia-a-dia do aluno. O mesmo parece ocorrer com P4 que, a princípio, diz não poder discordar para, em seguida, discordar. Pode ser que o entrevistado não tenha uma leitura direta do documento e, imaginando que o entrevistador conheça muito sobre o tema, prefira assumir uma posição de desconhecimento.

Ao assumir o papel de analista diante de entrevistas, o pesquisador precisa estar atento à ocorrência do mecanismo de antecipação, pois as falas dos entrevistados estão perpassadas por suas expectativas. Ao se expressar em uma situação de entrevista, o sujeito tende a antecipar o que o entrevistador quer ouvir sobre determinado tema e isso aparece em sua fala. É papel do analista então conhecer este mecanismo e considerá-lo no momento da análise.

\section{6 - Considerações sobre algumas das condições de produção das leituras dos professores.}

Neste trabalho, buscamos mostrar o papel da análise do discurso, referencial teórico-analítico, enquanto ferramenta para a análise de entrevistas. A história das leituras dos professores de ciências entrevistados através dos seus relatos sobre experiências de sucesso ao lecionar ciências no ensino fundamental e também de sua relação com os PCN's possibilitam melhor contextualizar suas leituras sobre o ensino de ciências. Em relação às condições de produção das leituras, estas dão origem a formações imaginárias que, segundo ORLANDI (1996, p.128) são compostas:

... de três coisas que presidem a argumentação em termos de discurso: relação de forças (lugares "sociais" e posição relativa no discurso), relação de sentido (o "coro de vozes" em um dizer; a relação que existe entre os vários discursos) e a antecipação... (grifos meus)

Neste caminho, compreendendo as histórias de sucesso dos professores e suas impressões sobre os PCN’s como participantes das condições de produção de suas leituras alguns pontos chamaram nossa atenção e merecem destaque: 
Em primeiro lugar, destacamos algumas das relações de forças presentes em seus dizeres:

* O lugar social "professor de ciências” engloba algumas tentativas de superar o ensino tradicional, através da procura e implementação principalmente de novas metodologias e também de novas formas de conceber o ensino de ciências e seus objetivos;

* Em alguns momentos os professores narram suas histórias de sucesso e sua visão dos PCN’s em primeira pessoa, apoderando-se de sua posição professor: eu fiz, nós colocamos em prática,... Em outros momentos, no entanto, colocase em outra posição, fora dos acontecimentos: os professores não leram, eles não têm acesso... Os professores parecem afastar-se da realidade vivenciada para poderem enxergá-la em todos os seus aspectos, inclusive as dificuldades.

Em segundo lugar, encontramos algumas das relações de sentidos presentes em sua fala, referentes à relação que existe entre um texto e outros, à memória discursiva:

* O discurso dos PCN’s sobre o ensino de ciências parece estar presente nas falas dos professores entrevistados, transparecendo em sua busca por relações entre ciência, tecnologia e sociedade e na utilização do cotidiano do aluno na sala de aula, por exemplo. Assim sendo, os PCN’s não são inócuos, porém eles carregam e disseminam tanto tentativas de avanço no que se refere ao ensino de ciências quanto algumas limitações;

* De certa forma, a pesquisa em educação também se encontra presente em seus discursos quando colocam os trabalhos com projetos, e no incentivo à autonomia dos alunos, entre outros. Por outro lado, destacamos que muitos destes saberes são construídos na própria escola, no fazer pedagógico e também na troca de idéias entre colegas;

* O coro de vozes presente nestas falas indica várias leituras sobre o ensino de ciências, entre as quais os professores muitas vezes têm procurado se posicionar, a fim de sair da situação de professor tradicional;

* Os professores não fizeram menções à utilização da história da ciência no ensino nem em suas histórias de sucesso nem em suas leituras sobre os PCN's e, considerando que o que não foi dito significa tanto quanto o que foi dito, esta ausência irá se refletir na fala dos professores de ciências sobre a história da ciência. 
Vol. 10 no. 1 jun. 2008

E, finalmente, também teve lugar no discurso dos professores a ocorrência do mecanismo de antecipação,por exemplo em momentos nos quais os estes não assumiam um conhecimento, mesmo que indireto, dos documentos oficiais. $\mathrm{O}$ mecanismo da antecipação para a Análise do Discurso de Linha Francesa diz respeito ao fato de que o locutor muitas vezes supõe o que o outro vai pensar. Estando numa situação de entrevista, sendo questionado sobre os PCN's, pode ser que o professor imagine que criticar os documentos não seja uma boa resposta a uma pergunta feita por um estudante de mestrado.

\section{7 - Considerações Finais}

A utilização da análise do discurso enquanto referencial analítico exige em grande parte sua incorporação como referencial teórico, pois se trata de lançar um olhar diferenciado à prática da pesquisa em um contexto de trabalho com material simbólico. Assim, sua utilização apenas como ferramenta de análise de dados empíricos impede a amplitude de olhar necessária a este tipo de trabalho.

Se tratando de "dados" referentes a entrevistas, a configuração das condições de produção das leituras dos entrevistados se mostrou bastante relevante. As condições de produção permitiram o acesso aos posicionamentos que os entrevistados assumiram em suas falas, auxiliando a compreensão das mesmas. Conceitos como o não dito e o mecanismo de antecipação também se mostraram importantes no momento de lançar olhares sobre as falas dos entrevistados.

Por fim, acreditamos que, enquanto pesquisadores em educação, não podemos nem devemos mais assumir uma visão de linguagem transparente, na qual o sentido está grudado nas palavras, que nos informam exatamente aquilo que estamos lendo. Dentro desta visão, a análise do discurso possibilita uma nova forma de olhar para a pesquisa e, principalmente, para as falas dos sujeitos pesquisados. 


\section{REFERÊNCIAS BIBLIOGRÁFICAS}

ASTOLFI, Jean Pierre et all. As palavras-chave da didáctica das ciências. Lisboa: Editora Horizontes Pedagógicos.

AGUIAR JR, Orlando G.; LIMA,Maria Emília Caixeta Castro; MARTINS, Carmem Maria de Caro. A formação de conceitos científicos: reflexões a partir da produção de uma coleção de livros didáticos. In: Atas do V Encontro Nacional de Pesquisa em Educação em Ciências. Bauru, SP, 2005. (CD-ROM)

AMARAL, Edenia Maria Ribeiro do; MORTIMER, Eduardo Fleury. Proposta metodológica para a análise da dinâmica discursiva em sala de aula. In: Atas do $\mathrm{V}$ Encontro Nacional de Pesquisa em Educação em Ciências. Bauru, SP, 2005. (CDROM)

CARVALHO, Ana Maria Pessoa; VANNUCCHI, Andréa Infantosi; BARROS, Marcelo Alves et all. Ciências no ensino fundamental: o conhecimento físico. São Paulo: Scipione,1998.

DELIZOICOV, Demétrio ; ANGOTTI, José André Peres. PERNAMBUCO, Marta M. Ensino de ciências: Fundamentos e métodos - Coleção docência e formação. São Paulo: Cortez, 2002.

FERREIRA, Rosângela dos Santos; LORENCINI JR, Álvaro. A construção do conhecimento biológico nas séries iniciais: o papel das interações discursivas em sala de aula. In: Atas do V Encontro Nacional de Pesquisa em Educação em Ciências. Bauru, SP, 2005. (CD-ROM).

FLÔR, Cristhiane Cunha. Leituras dos professores de ciências do ensino fundamental sobre as histórias da ciência. Dissertação de Mestrado. Programa de Pós-graduação em educação Científica e Tecnológica: Universidade Federal de Santa Catarina, 2005.

GIRALDI, Patrícia Montanari e SOUZA, Suzani Cassiani. Um olhar sobre a linguagem em textos didáticos de citologia. In: Atas do $V$ Encontro Nacional de Pesquisa em Educação em Ciências. Bauru, SP, 2005. (CD-ROM)

HÉRNANDEZ, Fernando ; VENTURA, Montserrat. A organização do currículo por projetos de trabalho: o conteúdo é um caleidoscópio. Porto Alegre: Artes Médicas, 1998.

LIMA, Analice de Almeida e NUÑEZ, Isauro Beltran. As analogias no ensinoaprendizagem: uma contribuição à formação inicial de professores de química. In: Atas da $27^{a}$ Reunião Anual da Sociedade Brasileira de Química e XXVI Congresso Latino-Americano de Química.Salvador, BA, 2004. (CD-ROM)

MORTIMER, Eduardo Fleury.; MASSICAME, Thomas; TIBERGHIEN, Andrée; BUTY, Christan. Uma metodologia de análise e comparação entre a dinâmica discursiva de salas de aulas de ciências utilizando software e sistema de categorização de dados em vídeo: parte 1, dados gerais. In: Atas do V Encontro Nacional de Pesquisa em Educação em Ciências. Bauru, SP, 2005. (CD-ROM)

NAGEM, Ronaldo Luís; MARCELOS, Maria de Fátima. Analogias e metáforas no ensino de biologia: a árvore da vida nos livros didáticos. In: Atas do V Encontro Nacional de Pesquisa em Educação em Ciências. Bauru, SP, 2005. (CD-ROM)

ORLANDI, Eni Pulcinelli. A linguagem e seu funcionamento - As formas do discurso. $4^{\mathrm{a}}$ ed. Campinas, SP: Pontes, 1996. 


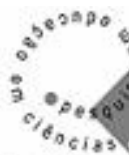 \\ ensa10}

Vol. 10 no. 1 jun. 2008

Análise de discurso: Princípios e procedimentos. Campinas,

SP: Pontes, $5^{\mathrm{a}}$ ed., 2003.

SCARPA, Daniela Lopes; TRIVELATO, Sílvia Luzia Frateschi. Investigando a construção de conhecimento científico em sala de aula por meio da análise de processos de enculturação: contribuições para a pesquisa. In: Atas do V Encontro Nacional de Pesquisa em Educação em Ciências. Bauru, SP, 2005. (CD-ROM)

SCHAFF, Adam. História e verdade. $2^{a}$. Ed. São Paulo, SP: Martins Fones Editora, 1983.

SCHAFFER, Deise Zamboni), REZENDE, Daisy de Brito. Representações do termo Orgânico para alunos ingressantes no Ensino Superior. In: Atas da $29^{a}$ Reunião Anual da Sociedade Brasileira de Química. Poços de Caldas, MG, 2006. (CD-ROM)

SILVA, Henrique César. Metodologia de pesquisa em ensino de física. In: Atas do IX EPEF. Jaboticatubas, SP, 2004.

SOUZA, Suzani Cassiani. Leitura e fotossíntese: Proposta de Ensino numa abordagem cultural. Tese de doutorado. Faculdade de Educação: Universidade Estadual de Campinas, 2000.

VILLANI, Alberto; CARVALHO, Lizete Orquiza. Discursos do professor na aprendizagem de física. In: Atas do V Encontro Nacional de Pesquisa em Educação em Ciências. Bauru, SP, 2005. (CD-ROM)

YORE, Larry D.; BISANZ, Gay L.; HAND, Brian M. Examining the literacy component of science literacy: 25 years of language arts and science research. In: Internacional Journal of Science Education. v.25, n.6, p.689-725, 2003. 